\title{
STUDY ON THE COURSE \\ OF CRYPTOSPORIDIUM BAILEYI INFECTION \\ IN CHICKENS TREATED WITH INTERLEUKIN-1 OR INDOMETHACIN
}

\author{
S. HORNOK ${ }^{1}$, Z. SZÉLL ${ }^{1}$, Tatjana A. SHIBALOVA ${ }^{2}$ and I. VARGA ${ }^{1 *}$ \\ ${ }^{1}$ Department of Parasitology and Zoology, University of Veterinary Science, H-1078 \\ Budapest, István u. 2, Hungary; ${ }^{2}$ The Saint-Petersburg State Academy of Veterinary \\ Medicine, Russia
}

(Received October 20, 1998; accepted December 1, 1998)

\begin{abstract}
The effects exerted by human recombinant interleukin-1 $\beta$ (hrIL-1 $\beta$ ) and the prostaglandin inhibitor indomethacin on the course of Cryptosporidium baileyi infection in chickens were studied. Daily oocyst shedding was monitored by a quantitative method throughout the experiment. Humoral immune response to C. baileyi was assessed by ELISA at 3 weeks of age while the level of cellular immune response to phytohaemagglutinin-P (PHA-P) by a skin test at 23 days of age. Parenteral application of hrIL-1 $\beta$ decreased oocyst shedding to $62 \%$, but the infection ran a similar course in treated and control birds. The PHA-P skin test demonstrated increased cellular immune reaction in chickens receiving IL-1 $\beta$, but there was no significant difference in the humoral responses of the two groups as detected by ELISA. On the other hand, indomethacin mixed to the feed lessened oocyst shedding to $13.7 \%$ and also shortened its duration. Immunological parameters as reflected by PHA-P skin test and ELISA results indicated enhanced cellular but unaltered humoral immune response. These data suggest that the systemic application of interleukin-1 can induce partial protection against $C$. baileyi in chickens and that prolonged, abundant oocyst shedding is due to an indomethacin-sensitive immunodepression via the prostaglandin pathway.
\end{abstract} domethacin

Key words: Cryptosporidium baileyi, chicken, cytokine, interleukin-1, in-

Cryptosporidium baileyi is a widespread coccidian parasite of most avian species (Lindsay and Blagburn, 1990) that can inhabit the microvillous brushborder of epithelial cells lining the respiratory, alimentary and urinary tracts. Oral experimental infection of chickens with $C$. baileyi oocysts does not always

\footnotetext{
* Corresponding author: Prof. I. Varga, Department of Parasitology and Zoology, University of Veterinary Science, H-1400 Budapest, P.O. Box 2, Hungary; E-mail: ivarga@ns.univet.hu; Fax: (36 1)3427701
} 
produce clinical signs (Current et al., 1986), although naturally occurring enteroepithelial cryptosporidiosis can result in weight loss, weakness and diarrhoea (Gorham et al., 1987).

During the development of immunity to pathogens avian macrophages produce interleukin-1 (IL-1) which acts on granulocytes and lymphocytes, e.g. by inducing $\mathrm{T}$ cell proliferation (Klasing, 1991). When T lymphocytes promoting the cellular immune response are activated, they release IL-2, an important cytokine for the differentiation of T and B lymphocytes, NK cells and macrophages of birds (Kaiser, 1996). In situ synthesized prostaglandins (PGs), especially $\mathrm{PGE}_{2}$, suppress IL-2 production in mammals (Chouaib et al., 1984), while indomethacin can reverse this action via inhibition of PG synthesis (Vane, 1971). A similar role of indomethacin has been found in chickens (Macari et al., 1993).

IL-1 was demonstrated earlier as an important factor in controlling infection of chickens with closely related Eimeria spp. (Byrnes et al., 1993) and IL-2 decreased oocyst shedding and disease susceptibility during chicken coccidiosis (Isobe and Lillehoj, 1993). The pivotal role of T cells in the expulsion of primary, and resistance to secondary, infection with $C$. baileyi was suggested, as both chemical or surgical thymectomy of chickens (Hatkin et al., 1993; Sréter et al., 1996) and abrogation of macrophage phagocytic activity (Ree et al., 1994) resulted in the establishment of reinfection. However, information is still lacking on the role of IL-1 and immunoregulatory PGs during experimental cryptosporidiosis of chickens.

The chicken IL-1 receptor has $60 \%$ amino acid sequence homology with its human counterpart (Guida et al., 1992), and human recombinant IL-1 $\beta$ improved vaccination against numerous poultry pathogens (Ananiev et al., 1997). On the other hand, the chicken IL-1 has been only partially purified (Klasing and Peng, 1987). Thus the purpose of the present study was to provide information on the role of IL-1 and on the effect of PG-inhibitor indomethacin on the outcome of experimental cryptosporidiosis, assuming that human IL-1 $\beta$ has similar effects in man and in chicken (Rothwell, 1991; Macari et al., 1993) and that orally administered cyclo-oxygenase inhibitors could reverse suppressed IL-2 production in mammals (Endres et al., 1990).

\section{Materials and methods}

\section{Experimental design}

Newly hatched chickens were randomly assigned to groups of 12 birds kept with continuous illumination in electrically heated, wire-bottomed cages. Feed and water were available ad libitum. The basal diet (Bábolna Co., Bábolna, 
Hungary) consisted of a commercial-type starter ration that contained $20.3 \%$ crude protein and had been specially formulated to exclude anticoccidials, antioxidants and antibiotics.

The study was performed in two parts (Experiment 1 and Experiment 2). In Experiment 1 one group of Arbor Acres chickens (IL1) received a daily intramuscular injection of $5 \mathrm{ng}$ human recombinant interleukin-1 $\beta$ (ARIVETIN ${ }^{\mathrm{TM}}$, described by Ananiev et al., 1997) from Day 6 until Day 11, and another group served as control (IC1). In Experiment 2 one group of Tetra-H chickens (IND) was fed with indomethacin mixed to their feed at $100 \mathrm{mg} / \mathrm{kg}$ from Day 6 . Birds of the same breed and age served as controls (IC2). The chickens were weighed at the age of 23 days.

Oocysts of C. baileyi were originally isolated from an outbreak in Hungary (Dobos-Kovács et al., 1994) and were maintained by serial passages in chickens. Isolation, storage and preparation of the inoculum were performed as described by Current et al. (1986). At the age of 1 week, chickens were inoculated orally with $8 \times 10^{5}$ C. baileyi oocysts. From Day 4 postinfection (PI) the total faeces of all groups was removed and weighed daily. The oocyst content for each 24-h period was determined by a quantitative method described previously (Varga et al., 1995). When oocysts were not found by this technique, faecal samples were checked with Sheather's sugar flotation method utilizing its higher sensitivity to detect low-level infections (Current, 1990).

\section{ELISA}

Blood samples were taken from all chickens at 3 weeks of age. Sera were stored at $-20{ }^{\circ} \mathrm{C}$ until use. For antigen preparation oocysts were purified by sucrose-gradient centrifugation as described by Ortega-Mora et al. (1992). The oocysts were finally collected in phosphate-buffered saline (PBS) containing $2 \mathrm{mM}$ phenylmethylsulfonyl fluoride (PMSF), $1 \mathrm{mM}$ ethylenediamine tetra-acetic acid (EDTA) and $0.25 \mathrm{mM}$ trans-epoxysuccinyl-L-leucylamido-(4-guanidino) butane (Sigma, St. Louis, USA), homogenized, and subjected to three freeze-thaw cycles involving incubation in liquid nitrogen for $10 \mathrm{~min}$ and subsequent thawing at $37^{\circ} \mathrm{C}$. The resulting suspension was centrifuged at $17,000 \mathrm{~g}$ at $4{ }^{\circ} \mathrm{C}$ for $30 \mathrm{~min}$. The supernatant was collected and the protein concentration determined according to the method of Bradford (1976). ELISA plates were coated with this antigen in $0.06 \mathrm{M}$ carbonate buffer ( $\mathrm{pH} 9.6)$ at a concentration of $1 \mu \mathrm{g}$ protein in $100 \mu \mathrm{l}$ per well at $4{ }^{\circ} \mathrm{C}$ overnight. Further steps of the ELISA were performed according to the method described earlier (Hornok et al., 1996) except that no second antibody was used and plates were incubated with rabbit anti-chicken IgG conjugated to horseradish peroxidase (Nordic, Tilburg, The Netherlands) at a dilution of 1:1000. 


\section{PHA-P skin test}

At the age of 23 days the birds were injected intradermally between the $3^{\text {rd }}$ and $4^{\text {th }}$ digits of the right foot with $100 \mu \mathrm{g}$ phytohaemagglutinin-P (Sigma) in $0.1 \mathrm{ml}$ sterile physiological saline solution (PSS). The left foot was similarly injected with $0.1 \mathrm{ml}$ PSS to serve as a control. The response to PHA-P and PSS was evaluated by determining the thickness of the interdigital skin with a micrometer $12 \mathrm{~h}$ after injection (Corrier and DeLoach, 1990). The cutaneous PHA$\mathrm{P}$ response was calculated as follows: swelling $=($ PHA-P post-injection thickness) - (PSS post-injection thickness).

\section{Statistics}

Mean values were compared by $t$-test and differences were considered significant when $\mathrm{P}<0.05$.

\section{Results}

To compare the susceptibility of two breeds to C. baileyi, Arbor Acres and Tetra-H chickens were used in Experiment 1 and Experiment 2, respectively. The prepatent period was 5 days in all groups. In Experiment 1 intramuscular application of hrIL-1 $\beta$ for 6 days resulted in a decrease of oocyst shedding to $62 \%$ in Group IL1 when compared to the controls (IC1) (Table 1), but it did not shorten the patency and the infection ran a similar course in the two groups (Fig. 1). Optical density (OD) values at serum dilution 1:80 in the ELISA performed at 3 weeks of age and mean body weights (MBWs) showed no significant difference between IC1 and IL1 chickens. Skin thickness of IL-1 treated chickens was significantly higher than that of IC1 birds in the PHA-P skin test $(\mathrm{P}<0.01)$ (Table 1).

In Experiment 2, oral continuous indomethacin uptake diminished the amount of oocysts shed by Group IND to $13.7 \%$ of that of the controls (IC2) (Table 1), and also shortened its duration by 5 days. Differences in the course of mean individual $C$. baileyi oocyst shedding between these groups were more apparent towards the end of the infection (Fig. 2). ELISA OD values indicated no alteration in humoral responses of IND chickens when compared to IC2 ones 2 weeks postinfection, whereas the PHA-P skin test demonstrated significantly enhanced cellular immunity $(\mathrm{P}<0.01)$ (Table 1$)$. There was no significant difference between the MBWs of the groups in Experiment 2. However, the MBW of Arbor Acres chickens in Experiment 1 was significantly higher than that of Tetra-H ones in Experiment 2 (data not shown). 


\section{Table 1}

Different parameters in chickens inoculated with $8 \times 10^{5}$ Cryptosporidium baileyi oocysts at 1 week of age, including mean total oocyst shedding (TO/group) in millions, the length of the patent period in days, optical density (OD) values in the ELISA at 3 weeks of age at serum dilution 1:80 (multiplied by 1000) and skin thickness in phytohaemagglutinin (PHA) skin test in millimetres $(\mathrm{mm})$ at 23 days of age

\begin{tabular}{lcccc}
\hline & \multicolumn{1}{c}{$\mathrm{IC1}^{*}$} & \multicolumn{1}{c}{$\mathrm{IL}^{\dagger}$} & $\mathrm{IC2}{ }^{* *}$ & $\mathrm{IND}^{*}$ \\
\hline TO/group $\left(10^{6}\right)$ & 1345.2 & 835.2 & 1617.6 & 222 \\
Patency (days) & 13 & 13 & 16 & 11 \\
ELISA OD $\times 1000$ & $341.4 \pm 188.5$ & $322.3 \pm 189.1$ & $428.9 \pm 160.5$ & $452.4 \pm 140.7$ \\
PHA thickness $(\mathrm{mm})$ & $0.475 \pm 0.144$ & $0.696 \pm 0.194$ & $0.31 \pm 0.189$ & $0.594 \pm 0.104$ \\
\hline
\end{tabular}

"Infected control (Experiment 1); "Interleukin-1 treated group, parenterally receiving hrIL-1 from 6 to 11 days of age; " Infected control (Experiment 2); "Indomethacin-treated group, receiving $100 \mathrm{mg}$ per kg of feed from 6 days of age

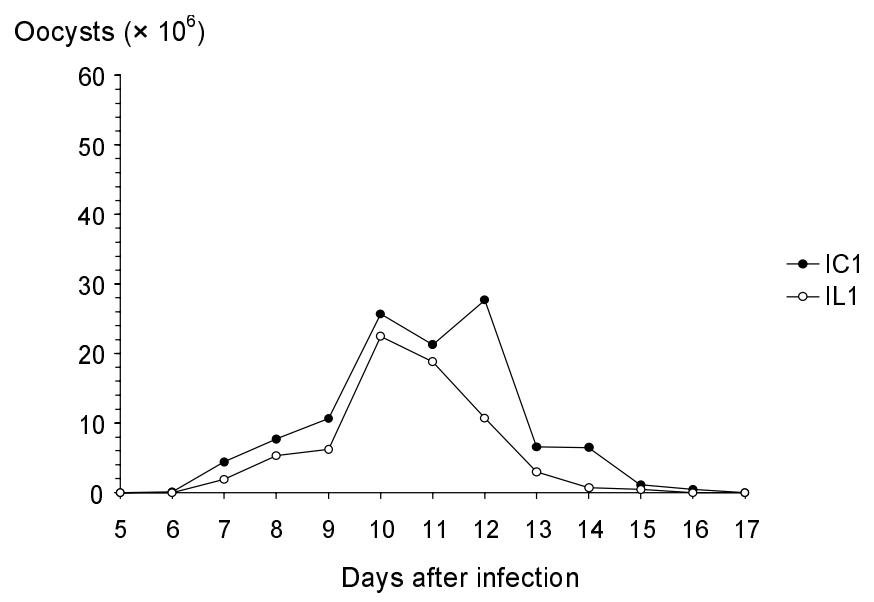

Fig. 1. Mean daily individual oocyst shedding of IC1 (infected control) chickens and IL1 chickens (receiving hrIL-1 parenterally from 6 to 11 days of age) in Experiment 1. Birds in both groups were inoculated with $8 \times 10^{5}$ Cryptosporidium baileyi oocysts at 1 week of age

\section{Discussion}

IL-1, IL-2 and $\mathrm{PGE}_{2}$ are important regulators of cellular immune responses. Peripheral IL-1 $\beta$ production is increased during infection and inflammation (Ulich et al., 1990). IL-1 was found to play an important role in chicken coccidiosis (Byrnes et al., 1993) and cells of Eimeria-infected chickens had greater capacity to produce it. The $60 \%$ amino acid sequence homology between 
human and avian IL-1 receptor (Guida et al., 1992) may reflect functional homology between phylogenetically conserved molecules (Heguy et al., 1992) which was further substantiated by successful induction of fever response following parenteral hrIL-1 $\beta$ application in both man and chicken (Rothwell, 1991; Macari et al., 1993). In Experiment 1 parenteral application of human recombinant IL- $1 \beta$ reduced oocyst shedding by $38 \%$ without a major effect on the course of the infection. Being the key cytokine of the macrophage-T cell interaction in birds (Klasing, 1991; Klasing, 1994; Qureshi et al., 1994), it enhanced the proliferation of chicken lymphocytes in the PHA-P skin test. On the other hand, it did not alter the humoral response to $C$. baileyi at 2 weeks postinfection, when the biggest differences had been demonstrated earlier between infected and uninfected chickens (Hornok et al., 1998b), confirming that circulating antibody levels show no correlation with protection during cryptosporidiosis (Hornok et al., 1996).

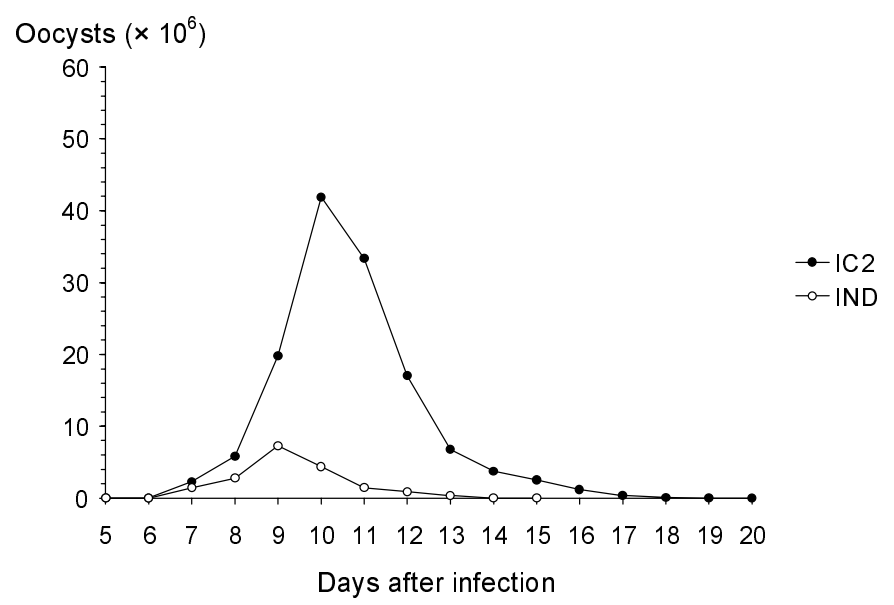

Fig. 2. Mean daily individual oocyst shedding of IC2 (infected control) chickens and IND chickens (receiving $100 \mathrm{mg}$ indomethacin per $\mathrm{kg}$ of feed from 6 days of age) in Experiment 2. Birds in both groups were inoculated with $8 \times 10^{5}$ Cryptosporidium baileyi oocysts at 1 week of age

PGs, especially $\mathrm{PGE}_{2}$, can inhibit IL-2 synthesis and production by mammalian T cells (Chouaib et al., 1984). Although cytokine production can also be suppressed by a PG-independent pathway (Stevens and Olsen, 1994), orally administered cyclo-oxygenase inhibitors (such as aspirin and indomethacin) increase IL-2 production (Endres et al., 1990), and indomethacin can restore and significantly increase IL-2 levels during protozoan infections of mammals (Calabresi et al., 1992). PGs are often associated with parasite-induced immunosuppression via inhibition of IL-2 secretion (Cillari et al., 1986; Tarleton, 1988). 
IL-2 was also shown to decrease the susceptibility of chickens to coccidiosis and Eimeria oocyst shedding (Isobe and Lillehoj, 1993).

In Experiment 2, the PG inhibitor indomethacin was very effective in decreasing the reproductive potential of $C$. baileyi and in accelerating its expulsion. It also caused an increased cellular, cutaneous basophil hypersensitivity reaction to PHA-P. Since this is a thymus-dependent response mediated by $\mathrm{T}$ cells (Stadecker et al., 1977), it suggests the involvement of IL-2 (Kaiser, 1996). The opposite can be observed when dexamethasone depresses IL-2 production and enhances oocyst shedding during chicken coccidiosis (Isobe and Lillehoj, 1993).

On the other hand, the application of indomethacin might have also induced effects other than increased IL-2 production, such as reversing the inhibitory effect of locally liberated PGs on leukocyte migration (Bonta and Parnham, 1979), antibody-dependent cell-mediated cytotoxicity (Droller et al., 1978) and NK cell activity (Gendron et al., 1992). Indomethacin promotes the migration of polymorphonuclear leukocytes into inflamed tissue (Higgs and Flower, 1981) and NK cell activity (Gogu and Blumberg, 1992). It was also reported to inhibit PGmediated stimulation of anion secretion and suppression of $\mathrm{NaCl}$ absorption during cryptosporidiosis (Argenzio et al., 1993). However, this cyclo-oxygenase inhibitor would not be suggested for therapy, since it is ulcerogenic (Prescott, 1976).

Differences between the parasitological parameters and ELISA results of the control groups reflect breed variation of chickens in susceptibility to C. baileyi infection. Since Tetra-H chickens shed more oocysts, the reproductive potential of this parasite seems to be independent of the body weight of its host.

Parenteral application of $C$. baileyi oocyst extract and maternal immunity conferred by hens resulted in a reduction of oocyst shedding to $60 \%$ and $45 \%$, respectively (Hornok et al., 1996; Hornok et al., 1998a). On the other hand, the oral inoculation of $C$. parvum oocysts into chickens yielded $83 \%$ protection to C. baileyi challenge (Sréter et al., 1997). The findings of the present study with the highest (more than $86 \%$ ) protection reported so far confirm the pivotal role of local, cellular mechanisms in the elimination of $C$. baileyi infection, and suggest that prolonged, abundant oocyst shedding is due to an indomethacinsensitive immunodepression via the PG pathway.

\section{Acknowledgements}

The study was performed in the framework of the Hungarian Scientific Research Fund (OTKA) project T26057. We thank the contributions of J. Kisgergely and L. Haluska to this work. 


\section{References}

Ananiev, O. V., Ananieva, N. B. and Shibalova, T. A. (1997): Prevention of poultry associative disease through application of immunomodulator ARIVETIN ${ }^{\mathrm{TM}}$ (interleukin-1 $\beta$ ). In: Proceedings of the XIth International Congress of the World Veterinary Poultry Association (18-22 August 1997), p. 168.

Argenzio, R. A., Lecce, J. and Powell, D. W. (1993): Prostanoids inhibit intestinal NaCl absorption in experimental porcine cryptosporidiois. Gastroenterology 104, 440-447.

Bonta, I. L. and Parnham, M. J. (1979): Time-dependent stimulatory and inhibitory effects of prostaglandin $\mathrm{E}_{1}$ on exudative and tissue components of granulomatous inflammation in rats. Br. J. Pharmacol. 65, 465-472.

Bradford, M. M. (1976): A rapid and sensitive method for the quantitation of microgram quantities of protein utilizing the principle of protein-dye binding. Analyt. Biochem. 72, 248-254.

Byrnes, S., Eaton, R. and Kogut, M. (1993): In vitro interleukin-1 and tumor necrosis factor-alpha production by macrophages from chickens infected with either Eimeria maxima or Eimeria tenella. Int. J. Parasitol. 23, 639-645.

Calabresi, A., Perito, S., Romani, L. and Bistoni, F. (1992): Drug-induced modulation of IL-2 production in experimental murine trypanosomiasis. Int. J. Immunopharmacol. 14, 1165-1173.

Chouaib, S. L., Chatenoud, L., Klatzmann, D. and Fradelizi, D. (1984): Mechanism of inhibition of IL-2 production: PGE $_{2}$ induction by suppressor T-lymphocytes. J. Immunol. 132, 1851-1857.

Cillari, E., Liew, F. Y. and Lelchuk, R. (1986): Suppression of interleukin-2 production by macrophages in genetically susceptible mice infected with Leishmania major. Infect. Immun. 54, 386-394.

Corrier, D. E. and DeLoach, J. R. (1990): Evaluation of cell-mediated, cutaneous basophil hypersensitivity in young chickens by an interdigital skin test. Poultry Sci. 69, 403-408.

Current, W. L. (1990): Techniques and laboratory maintenance of Cryptosporidium. In: Dubey, J. P., Speer, C. A. and Fayer, R. (eds) Cryptosporidiosis of Man and Animals. CRC Press, Boca Raton, pp. 59-82.

Current, W. L., Upton, S. J. and Haynes, T. B. (1986): The life cycle of Cryptosporidium baileyi $\mathrm{n}$. sp. (Apicomplexa, Cryptosporidiidae) infecting chickens. J. Protozool. 33, 289-296.

Dobos-Kovács, M., Varga, I., Békési, L., Drén, Cs. N., Németh, I. and Farkas, T. (1994): Concurrent cryptosporidiosis and chicken anaemia virus infection in broiler chickens. Avian Pathol. 23, 365-368.

Droller, J. J., Schneider, M. V. and Perlmann, P. (1978): A possible role of prostaglandins in the inhibition of natural and antibody-dependent cell mediated cytotoxicity against tumor cells. Cell. Immunol. 39, 165-177.

Endres, S., Meydani, S. N., Ghorbani, R., Schindler, R., Dempsey, R. A. and Dinarello, C. A. (1990): Interleukin-2 production is suppressed by dietary N-3 fatty acids but enhanced by oral aspirin. Physiological and pathological effects of cytokines. In: Progress in Leukocyte Biology 10B, 281-286.

Gendron, R. L., Farookhi, R. and Baines, M. G. (1992): Murine pregnancies predisposed to spontaneous resorption show alterations in the concentrations of leukotriene B4 and prostaglandin E2. Biol. Reprod. 47, 72-75.

Gogu, S. R. and Blumberg, J. B. (1992): Vitamin E enhances murine natural killer cell cytotoxicity against YAC-1 tumor cells. J. Nutr. Immunol. 1, 31-38.

Gorham, S. L., Mallinson, E. T. and Snyder, D. B. (1987): Cryptosporidiosis in the bursa of Fabricius - a correlation with mortality rates in broiler chickens. Avian Pathol. 16, 205-211.

Guida, S., Heguy, A. and Melli, M. (1992): The chicken IL-1 receptor: differential evolution of the cytoplasmic and extracellular domains. Gene 111, 239-243. 
Hatkin, J., Giambrone, J. J. and Blagburn, B. L. (1993): Correlation of circulating antibody and cellular immunity with resistance against Cryptosporidium baileyi in broiler chickens. Avian Dis. 37, 800-804.

Heguy, A., Baldari, C. T., Macchia, G., Telford, J. L. and Melli, M. (1992): Amino acids conserved in interleukin-1 receptors (IL-1Rs) and the Drosophila toll protein are essential for IL-1R signal transduction. J. Biol. Chem. 267, 2605-2609.

Higgs, G. A. and Flower, R. J. (1981): Anti-inflammatory drugs and the inhibition of arachidonate lipoxygenase. In: Piper, P. J. (ed.) SRS-A and Leukotrienes. Research Studies Press, Chichester, New York, pp. 197-207.

Hornok, S., Sréter, T., Békési, L., Széll, Z. and Varga, I. (1996): Attempts to immunize chickens with Cryptosporidium baileyi oocyst extract. J. Parasitol. 82, 650-652.

Hornok, S., Bitay, Z., Széll, Z. and Varga, I. (1998a): Assessment of maternal immunity to Cryptosporidium baileyi in chickens. Vet. Parasitol. 79, 203-212.

Hornok, S., Széll, Z., Nieuwenhuijs, J., Nieuwland, M. G. B., Cornelissen, A. W. C. A. and Varga, I. (1998b): Immunogenicity of three oocyst extracts of Cryptosporidium baileyi in experimentally infected chickens. Parasitol. Res. (in press).

Isobe, T. and Lillehoj, H. S. (1993): Dexamethasone suppresses T cell-mediated immunity and enhances disease susceptibility to Eimeria mivati infection. Vet. Immunol. Immunopathol. 39, 431-446.

Kaiser, P. (1996): Avian cytokines. In: Davison, T. F., Morris, T. R. and Payne, L. N. (eds) Poultry Immunology. Carfax Publishing Company, Abingdon, U. K., pp. 83-114.

Klasing, K. C. (1991): Avian inflammatory response: mediation by macrophages. Poultry Sci. 70, $1176-1186$

Klasing, K. C. (1994): Avian leukocytic cytokines. Poultry Sci. 73, 1035-1043.

Klasing, K. C. and Peng, R. K. (1987): Influence of cell sources, stimulating agents, and incubation conditions on release of interleukin-1 from chicken macrophages. Develop. Comp. Immunol. 11, 385-394.

Lindsay, D. S. and Blagburn, B. L. (1990): Cryptosporidiosis in birds. In: Dubey, J. P., Speer, C. A. and Fayer, R. (eds) Cryptosporidiosis of Man and Animals. CRC Press, Boca Raton, pp. $133-148$.

Macari, M., Furlan, R. L., Gregorut, F. P., Secato, E. R. and Guerreiro, J. R. (1993): Effects of endotoxin, interleukin-1 $\beta$ and prostaglandin injections on fever response in broilers. Br. Poultry Sci. 34, 1035-1042.

Ortega-Mora, L. M., Troncoso, J. M., Rojo-Vazquez, E. A. and Gomez-Batista, M. (1992): Evaluation of an improved method to purify Cryptosporidium parvum oocysts. Res. Rev. Parasitol. 52, 127-130.

Prescott, L. F. (1976): Antipyretic analgetics. In: Dukes, M. N. G. (ed.) Meyler's Side Effects of Drugs 8, pp. 154-206.

Qureshi, M. A., Marsh, J. A., Dietert, R. R., Sung, Y. J., Nicolas-Bolnet, C. and Petitte, J. N. (1994): Profiles of chicken macrophage effector functions. Poultry Sci. 73, 1027-1034.

Ree, J. K., Jang, B. G. and Park, B. K. (1994): Oocyst production and immunogenicity of Cryptosporidium baileyi in chickens and mallards. J. Avian Biol. 25, 45-54.

Rothwell, N. J. (1991): Functions and mechanisms of interleukin-1 in the brain. Trends in Pharmacol. Sci. 12, 430-436.

Sréter, T., Varga, I. and Békési, L. (1996): Effects of bursectomy and thymectomy on the development of resistance to Cryptosporidium baileyi in chickens. Parasitol. Res. 82, 174-177.

Sréter, T., Hornok, S., Varga, I., Békési, L. and Széll, Z. (1997): Attempts to immunize chickens against Cryptosporidium baileyi with Cryptosporidium parvum oocysts and Paracox ${ }^{\mathrm{TM}}$ vaccine. Folia Parasitol. 44, 77-80. 
Stadecker, M. J., Lukic, M., Dvorak, A. and Leskowitz, S. (1977): The cutaneous basophil response to phytohemagglutinin in chickens. J. Immunol. 118, 1564-1568.

Stevens, M. G. and Olsen, S. C. (1994): In vitro effects of live and killed Brucella abortus on bovine cytokine and prostaglandin $\mathrm{E}_{2}$ production. Vet. Immunol. Immunopathol. 40, 149-161.

Tarleton, R. L. (1988): Trypanosoma cruzi-induced suppression of IL-2 production. Evidence for a role of suppressor cells. J. Immunol. 140, 2769-2773.

Ulich, T. R., Guo, K., Irwin, B., Remick, D. G. and Navatelis, G. N. (1990): Endotoxin-induced cytokine gene expression in vivo. Am. J. Pathol. 137, 1173-1185.

Vane, J. R. (1971): Inhibition of prostaglandin synthesis as a mechanism of action for aspirin-like drugs. Nature. New Biology 232, 232-235.

Varga, I., Sréter, T. and Békési, L. (1995): Quantitative method to assess Cryptosporidium shedding in the chicken model. Parasitol. Res. 81, 262-264. 